\title{
Promoção do turismo na Praia Grande (MA): entre a fantasia e a realidade no cenário do patrimônio cultural
}

\section{Promoting Tourism in Praia Grande (MA): between fantasy and reality in the set- ting of cultural heritage}

\section{Georgia Patrícia da Silva, Elizabete Melo Nogueira, Maria Neusa de Lima Pereira}

\begin{abstract}
RESUMO
Os diversos produtos culturais são fortes aliados para promover determinados destinos turísticos. Os centros históricos com acervo de patrimônios culturais, por exemplo, exercem grande influência no imaginário das pessoas e, por isso, quando associados ao marketing, podem criar cenários, expectativas e fantasias que despertam desejos nas pessoas, sendo algumas delas nem sempre alcançáveis na realidade. Este trabalho teve o objetivo de discutir a relação entre a promoção e a realidade no turismo do Centro Histórico de São Luís, notadamente do bairro Praia Grande- MA, cenário do patrimônio cultural, sob a ótica dos turistas. Para isso, foram consultados registros realizados pelos turistas no livro de protoloco da Secretaria do Turismo do Estado. Também foram realizadas algumas conversas, sob forma de consulta, com comerciantes locais, no intuito de cruzar as informações obtidas. Como resultado, pôdese perceber nos registros, que expressam a "voz" do turista, reforçada pela dos comerciantes a reclamação, o descontentamento, insatisfação e a cobrança por melhorias da infraestrutura, de acessos e atendimento quando se referem a um dos principais destinos turísticos da cidade. A fantasia tão propalada positivamente pelas mídias contradiz a realidade no cenário do patrimônio cultural.
\end{abstract}

PALAVRAS-CHAVE: Turismo; Marketing; Centro Histórico; Promoção; Patrimônio Cultural.

\section{ABSTRACT}

In a number of cultural products, tourism has strong allies in promoting certain tourist destinations in the cities. The historical centers with a collection of cultural assets, for example, exert a great influence on people imagination and, therefore, when combined with marketing, can promote creating scenarios, expectations and fantasies that create and arouse people's desire, some of them are in fact not always achievable. This study aimed to discuss the relationship between advertisement and reality in tourism in the Historical Center of São Luís, especially the district Praia Grande - MA, from tourists' view. To this were consulted registrations made by tourists in the protocol book from Tourism Secretariat of the State. Were also held some talks in consultation mode with local traders in order to cross the obtained information. As a result that could be seen in the records, which express the tourist's voice reinforced by the traders', it contains complaints, discontent, dissatisfaction and charging for infrastructure improvements as access and service, when referring to a major tourist destination in the state. The fantasy touted positively by the media, contradicts the reality on the scenario of cultural heritage.

KEYWORDS: Tourism, Marketing, Historical Center, Promotion, Cultural Heritage. 


\section{Introdução}

Sànches (2003) e Vainer (2000) têm levantado reflexões sobre a competição entre lugares, relacionando-as com as estratégias utilizadas pelos gestores das cidades, nas últimas décadas, para criar espaços atrativos. Nessa lógica, a capacidade de competitividade entre as diferentes regiões, países ou cidades vem se desdobrando em função de diversos fatores, tais como, localização, acervo cultural, personagens de destaque, bem como pelo uso do mix de marketing ${ }^{1}$, notadamente da promoção ${ }^{2}$ dos espaços urbanos, cuja principal missão seria a de incrementar o processo de venda dos lugares com seus não-lugares (AUGÉ, 1994)

De acordo com Sànchez (1999, p.115), a valorização do marketing seria fruto da atual conjuntura econômica mundial, a qual "se constitui na orientação da política urbana, a criação ou atendimento das necessidades do consumidor, seja este empresário, turista ou o próprio cidadão". Esse processo de valorização da imagem, inclusive no cenário internacional dessas cidades, foi acompanhado por uma "notável expansão dos departamentos e agências de comunicação e marketing, dentro das respectivas estruturas administrativas locais" (SÀNCHEZ, 1999, p.2).

É necessário frisar que a incorporação do marketing urbano ${ }^{3}$ revela uma nova ordem junto às demais práticas de gestão relacionadas, que buscam dar uma nova imagem às cidades ou reforçar o que eles têm de melhor. O sucesso "é tão claramente lucrativo que o investimento na construção de imagem [...] se torna tão importante quanto o investimento em novas fábricas e maquinário" (HARVEY, 2001, p. 260-261). A transformação de "imagens em simulacros materiais na forma de ambientes [...] construídos", consiste na "outra dimensão do papel mutante da espacialidade na sociedade contemporânea" (HARVEY, 2001, p. 266).

Biachini (1999) comenta que

já se percebia uma tendência em afastar as questões de caráter sociopolítico, predominante na década de 1970, e priorizar o desenvolvimento econômico e a regeneração urbana [...] Uma vida cultural cosmopolita foi sendo, gradualmente, entendida como um integrante crucial das estratégias de city marketing e de internacionalização, elaboradas para atrair turistas, capital internacional flutuante e profissionais especializados. (BIANCHINI, 1999, p79).

É nesse panorama lastreado pelo teor mercadológico que se descortina a "mercantilização" do espaço urbano (VAINER, 2000), que afasta a ideia romântica de que o poder público tem como prioridade ordenar o pleno desenvolvimento das funções sociais e garantir o bem estar da população quando se observa o espraiar de um ordenamento e medidas cada vez mais complexas, que potencializam profundas e efetivas transformações de natureza temporal e espacial.

No Maranhão, não é diferente. Para se inserir a capital do estado no circuito global do turismo foi utilizado, em termos midiáticos, um conjunto de técnicas de promoção, decorrendo o uso exacerbado do Centro Histórico, por ser um dos principais destinos turísti- 
cos do estado. Para isso, teve um esforço para a geração de valor que segue as tendências de mercado, resultando na constante busca pela diferenciação, a qual se traduziu na supervalorização de um dos "pedaços" do centro antigo: o Bairro Praia Grande ${ }^{4}$ (Figura 1).

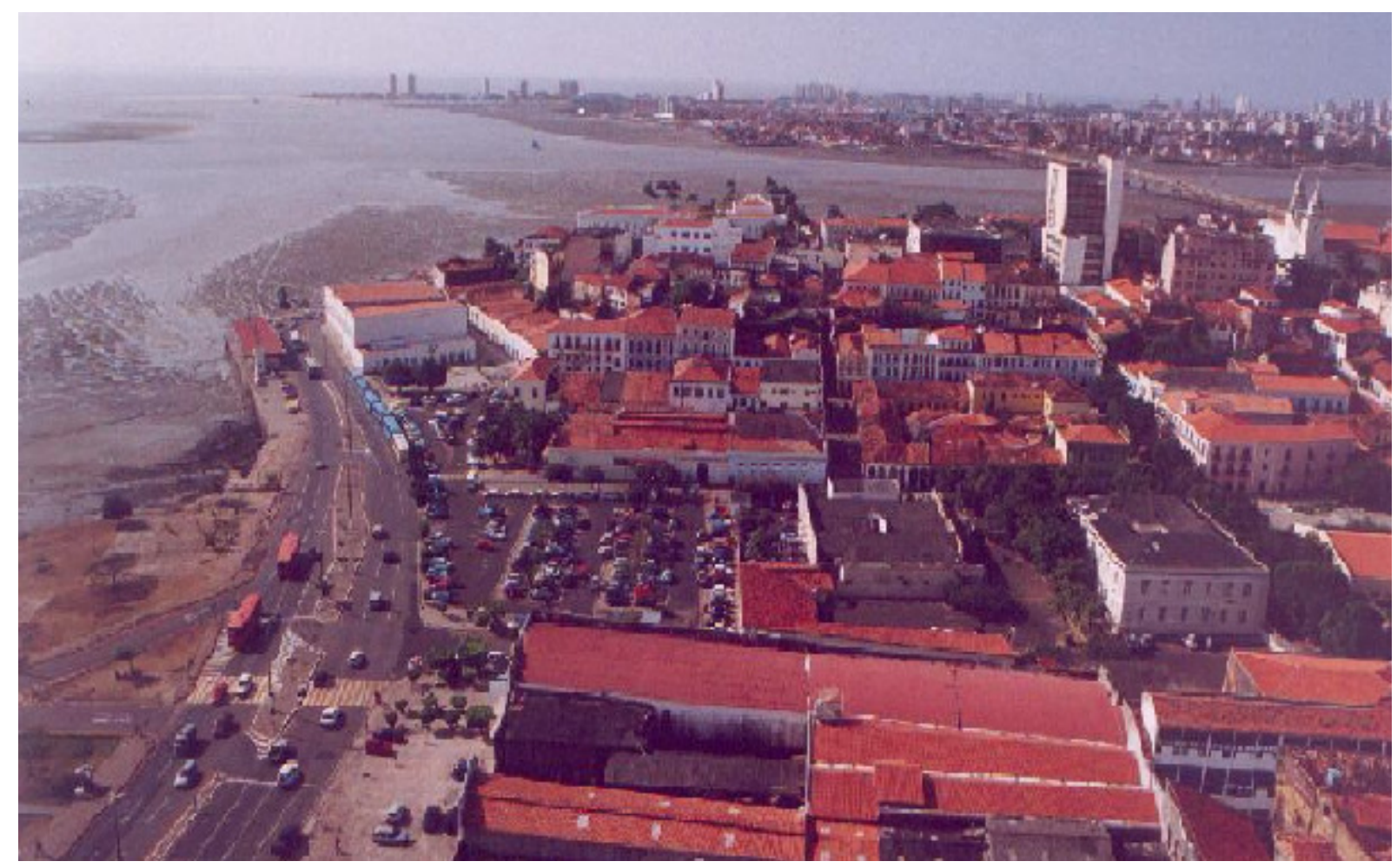

Figura 1: vista aérea do bairro Praia Grande. Foto: Santo e Marcelo (2006).

Figure 1: Aerial view of District Praia Grande. Photo: Santo and Marcelo (2006).

Nessa perspectiva, o processo de valorização do centro antigo, via Praia Grande, assumiu as características de produção de um espaço transformado em mercadoria, pensado e produzido como espetáculo, metamorfoseado para não parecer como tal, a fim de atrair compradores e capital mediante os interesses que legitimam e consubstanciam ações técnicas e políticas no espaço urbano.

Este artigo teve como objetivo discutir a relação entre a fantasia e a realidade no turismo do Centro Histórico de São Luís, sob a ótica dos turistas. Para isso, foram consultados comentários registrados no Livro de Protocolo da Secretaria de Turismo do Estado pelos turistas. Stamou e Paraskevopoulos (2004) utilizaram os discursos registrados em um livro por turistas em visita a um parque da Grécia para analisar as imagens construídas sobre o meio ambiente turístico natural, considerando-o como uma rica fonte de dados qualitativos, por serem narrativas pessoais espontâneas.

Para o desenvolvimento do estudo aqui apresentado, foi utilizado o método qualitativo de pesquisa, em que se privilegiou a pesquisa documental como técnica de coleta de dados, buscando analisar dados secundários e conversas informais com comerciantes do Bairro Praia Grande. A fim de manter o sigilo da autoria dos registros encontrados no livro 
de protocolo da Secretaria, foram omitidos os nomes, embora os turistas tenham se identificado e ainda disponibilizado, telefone, e-mail e por vezes as regiões de origem quando fizeram comentários no livro.

Foram analisadas ainda peças publicitárias presentes nos meios de comunicação, incluindo matérias publicadas no ambiente virtual, revistas e jornais, a fim de se compreender as representações do bairro Praia Grande, ao qual são atribuídos os valores que predominam no imaginário da sociedade, o que pode ser revelador sobre a imagem que se quer mostrar. Como resultado da reflexão sobre essa temática, este trabalho apresenta o bairro Praia Grande como recorte espacial, a fim de discutir os desdobramentos que envolvem a percepção dos turistas, sobretudo no que diz respeito às diferenças entre o que é propalado e sua vivência concreta no cenário do patrimônio cultural.

Adota-se como premissa que o processo de revalorização do centro antigo é qualificado pela estetização ${ }^{5}$ do patrimônio cultural e pelo discurso cujo conteúdo é a necessidade de preservar o acervo edificado, para que o espaço retome sua importância e venha a adquirir uma imagem de limpo, belo e seguro, onde se privilegia a cenarização cada vez mais falseada e menos pura, pelo fato de agregar formas e estilos que dissolvem as fronteiras das representações socioculturais. (LUCHIARI, 2002).

\section{O Bairro Praia Grande propagado na mídia}

O bairro Praia Grande, na cidade de São Luís, foi sede das primeiras atividades econômicas de médio e grande e primeiro quartel de centúria, tornando-se, por causa do porto, centro comercial onde se importavam e exportavam mercadorias controladas por militares e chefes do executivo da cidade, o que possibilitou a concentração de atividades comerciais e residenciais por muitos anos.

Segundo Reis (1990), o nome Praia Grande está associado às reentrâncias que se compunham na maré baixa, chamadas vulgarmente de praias. Existiam muitas delas que eram identificadas por nomes específicos, tais como Ribeirão, Santo Antônio e uma das maiores, que era conhecida como Grande, ou seja, a sua constituição natural "não era mais que um vaso paul ${ }^{6}$ deixado e refeito, a cada maré vazante" (MEIRELES; TEIXEIRA, 1979).

\footnotetext{
O mar, ontem como hoje, invadindo terra a dentro, emprestava à foz do lbacanga - que em verdade não passa de um modesto riacho insular - a largura quase majestosa de cerca de um quilômetro de extensão, como se fosse ele um verdadeiro a portentoso rio. Mas, a cada refluxo de suas ondas na intermitente oscilação das marés, deixa-lhe nas margens aquele lodaçal fétido que então se alargava, ladeando a Rua do Trapiche, desde a Rampa do Palácio ao pé do antigo Forte de São Luís, até a Rua da Estrela onde se confrontavam a Alfândega e o Arsenal da Marinha, e em o qual vinha descambar, em acentuado declive, a ladeira da Rua do Giz. (MEIRELES; TEIXEIRA, 1979, p.1).
}

A história do bairro ludovicense ${ }^{7}$ está intimamente ligada à história da própria cida- 
de, fundada em 1612 por Daniel de La Touche, Senhor de La Ravardière, autorizado pela rainha regente Maria de Médice, que escolheu um lugar estratégico para a fundação da colônia e do Forte de Saint-Louis, em homenagem a Luís XIII (OLIVEIRA, 1996).

Nesta área, em função da dinâmica social, houve a construção de grandes sobrados $^{8}$, que representam a opulência e riqueza da época (Figuras 2 e 3). Ainda hoje, tem na composição do tecido urbano uma concentração de edificações na maioria de três pavimentos e muitos delas apresentam materiais utilizados para a adequação ao clima local, tais como o uso de azulejos nos sobrados, aspecto que diferencia a área dos demais bairros do centro histórico, onde existem centenas de imóveis do período colonial e imperial, e início do século XX, caracterizados, sobretudo, por "telhados em telha de barro do tipo capa-e-canal, beirais curtos terminados com cimalhas trabalhadas, vãos estreitos regularmente dispostos e emoldurados, balcões guarnecidos de grades de ferro batido e piso em pedra de cantaria" (MARANHÃO, 1997, p.14).

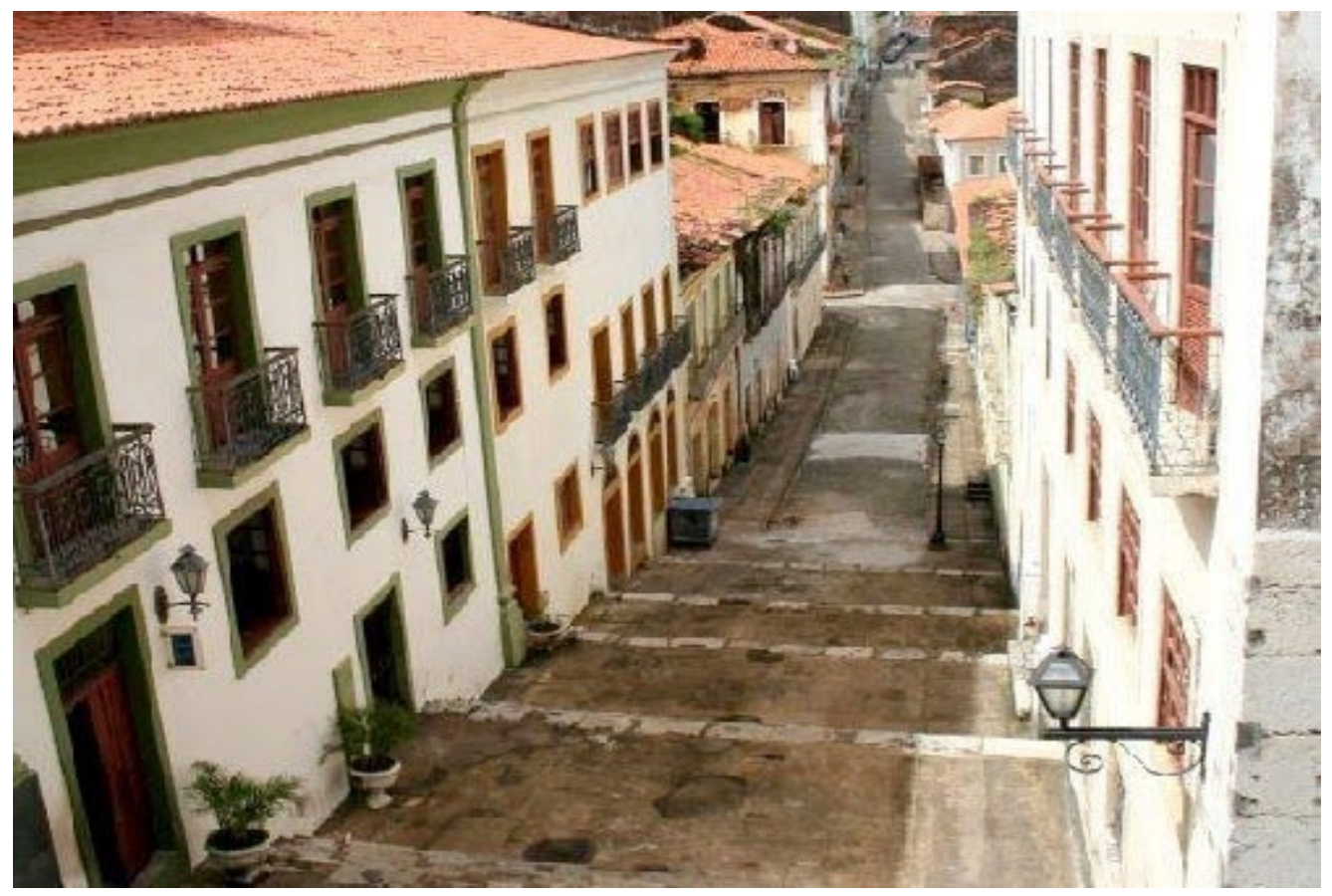

Figura 2: arquitetura de São Luís. Foto: GOVERNO DO ESTADO (2011).

Figure 2: Architecture of São Luis (MA, Brazil). Photo: State Government (2011).

O fato é que houve a perda de centralidade do centro tradicional resultante das dinâmicas e transformações dos processos de produção e consumo da cidade, o que ocasionou o interesse em outras áreas urbanas, bem como a maior oferta de habitações e de estabelecimento de comércios e serviços que passaram a ser mais atrativos, em virtude dos constantes investimentos públicos em prol da expansão da mancha urbana e do movimento de modernização da cidade de São Luís.

Neste sentido, a Praia Grande, por décadas ficou esvaziada e, principalmente, estigmatizada (ver detalhes em SILVA, 2010). Entretanto, na década de 1970, adquiriu contornos surpreendentes, pela habilidade do poder público que se inspirou nos equipamen- 
tos urbanos em desuso para atrair capital, conquistando o mercado e adeptos. Muitas das edificações vazias vieram a ser tombadas ${ }^{9}$ como patrimônios que estão, atualmente, sob proteção municipal, estadual e federal e muitas estão inscritas pela UNESCO como Patrimônio Mundial da Humanidade.

Hoje tombada como Cidade Patrimônio da Humanidade, guarda como herança da forte colonização lusitana a maior área de arquitetura colonial portuguesa existente no Brasil e uma das mais importantes do mundo. São mais de 3.500 edificações de valor histórico, no centro da cidade, que, segundo a UNESCO, representam "uma cultura e uma época, testemunho significativo da história da humanidade (BRASIL VIAGEM, 2009, s/p).

Um fator que ajudou a dar maior visibilidade à Praia Grande foi o Programa de Revitalização, no qual foram contempladas ações de saneamento e melhoria de infraestrutura. Concomitantemente, houve a emergência e a consolidação de um discurso baseado na construção social de uma imagem urbana e a linguagem da propaganda turística, evocando sedução, beleza, harmonia, descontração e felicidade.

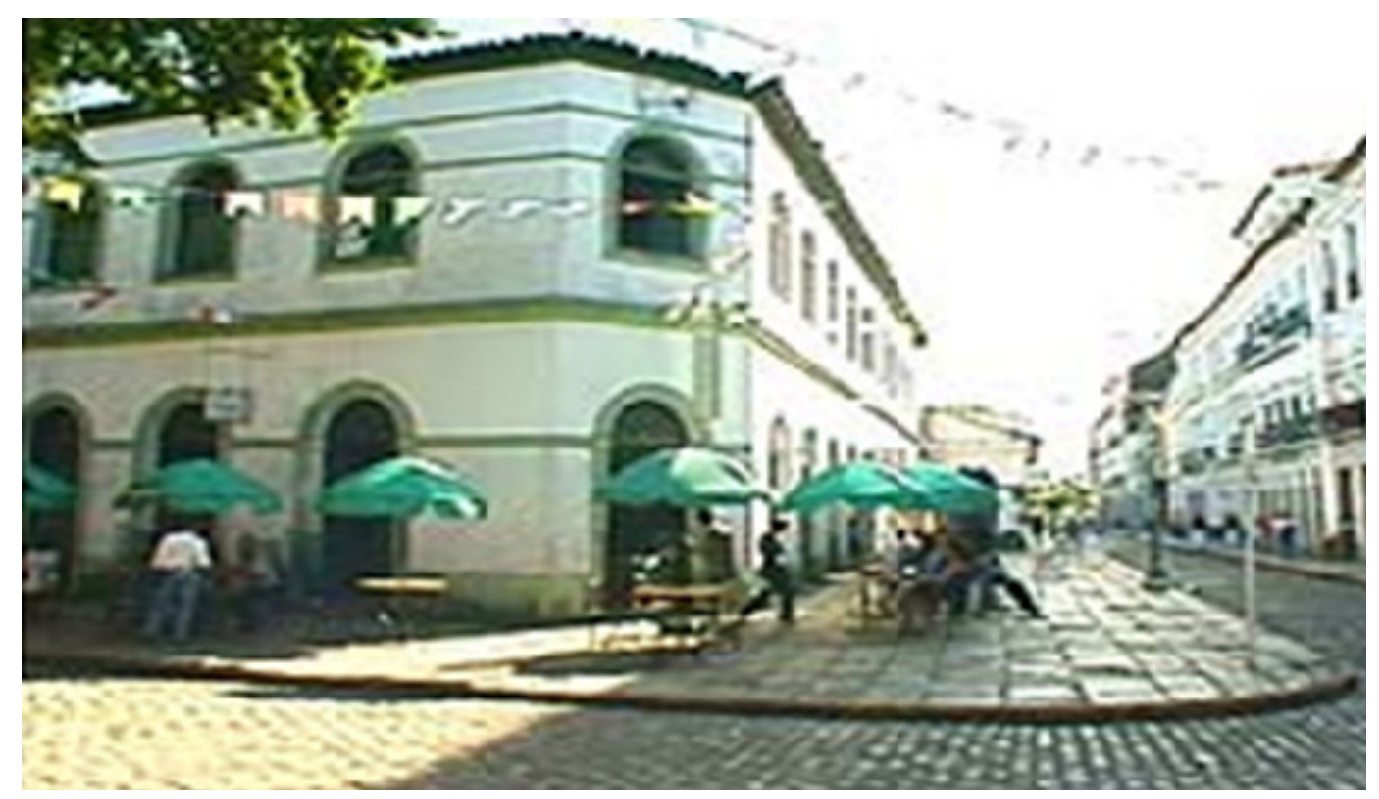

Figura 3: Bairro Praia Grande, rua da Estrela com rua Portugal. Fonte: Cidades Históricas Brasileiras (2009).

Figure 3: District Praia Grande, Street da Estrela with Portugal. Source: Cidades Históricas Brasileiras (2009).

No site oficial do Governo tem a seguinte propaganda, vinculando o patrimônio cultural ao "certificado" da UNESCO:

A área de casarões históricos de São Luís ocupa 250 hectares e envolve três mil e quinhentas construções. A beleza e a importância histórica deste acervo arquitetônico foram reconhecidas em 1997, pela Organização 
das Nações Unidas para a Educação e Cultura (UNESCO), que concedeu à cidade o título de Patrimônio Cultural da Humanidade.Para concessão do título, também foi levada em conta a preservação dos prédios antigos e a revitalização dos bairros que formam o Centro Histórico (especialmente a Praia Grande, obra iniciada na década de 70 e retomada a partir de 1987, com o Projeto Reviver) (GOVERNO DO ESTADO, 2009, s/p).

As fases de formulação e implementação de Programa de Preservação e Revitalização Urbana soaram como uma estratégia de (re)apropriação do espaço devido à exploração de elementos simbólicos, estéticos, sociais e culturais, com implicações na composição urbana pouco divulgadas, a exemplo da proibição dos hippies em determinadas ruas.

A partir de agora, estamos positiva e definitivamente revertendo o processo de deterioração da Praia Grande. Agora que o Maranhão confirma sua vocação de grande Estado, trilhando os caminhos do desenvolvimento, torna-se altamente necessário garantir a memória de épocas igualmente gloriosas (MARANHÃO, 1981, p.03).

Entende-se que o poder público não inventou o bairro Praia Grande com suas propagandas, mas é responsável por transformar uma visão ou interpretação de imagem do cotidiano no mundo fantástico do espetáculo. Das ruínas, do abandono e da decadência, vem nova identidade, não só por aquilo que é, mas pelo modo como é apresentada. O lugar, aparentemente esquecido, recebe um teor magicamente perfeito, que o torna único e adorável.

O conjunto da Praia Grande é formado por ruas, becos, travessas e escadarias que se constituíram por muitos anos no centro comercial de São Luís. Hoje, guarda a memória de um tempo de esplendor e opulência. É um patrimônio cultural único - orgulho, coração e alma da cidade (PATRIMÔNIO DA HUMANIDADE, 2009, s/p).

O bairro da Praia Grande, permeado por um conjunto de bens culturais, fica reduzido a imagens e interpretações, produzidas, sobretudo, sobre pontos marcantes que são escolhidos para representar as tradições do que se deve observar. Este assunto é importante porque empenha a questão ideológica e pode contribuir para esclarecer a transformação dos monumentos históricos e marcos culturais ao culto narcisista do patrimônio.

A orientação publicitária que direciona como ver o bairro Praia Grande deve ser questionada pelo excesso de representação, quando leva a exigir a volta a uma forma mais tradicional da sociedade sem conflitos, onde não se veem as manchas da exploração que se estendeu sobre esse espaço durantes séculos.

Esta história fascinante (e ainda pouco conhecida), resultado de um feliz equilíbrio das circunstâncias históricas e geográficas, nos deixou um conjunto rico de traços culturais muito originais: um legado arquitetônico, literário e humano, contendo uma significação excepcional: um patrimônio monumental único em seu gênero. Na realidade, há traços semelhantes 
que dão ideia de um certo "ar familiar" em outras cidades do mundo que conheceram simbioses de cultura e de influências locais e coloniais, sobretudo de origem portuguesa (PORTOS-MA, 2009, s/p).

A apologia ao patrimônio tornou-se pedra de toque nas campanhas publicitárias. Nesse quadro pintado de beleza emergem expectativas que apresentam divergências quando são interpostas com a realidade. É necessário reconhecer que os efeitos dessa divulgação em torno da cultura que está na gênese dos centros históricos apontam resultados desastrosos, quando não estudo e planejamento urbano.

Não se pode voltar a apresentar a sociedade antiga, com pontuação de símbolos que demarcam a tradição de uma elite branca e classista. Talvez a melhor definição da Praia Grande seja essa dissociação entre a história e seus personagens. Sob os olhares, associa-se a lógica do mercado, que comanda a ideologia, cria o imaginário social, faz a releitura étnica da cidade, por meio de ações que valorizam a presença dos descendentes europeus.

Equivale dizer que nesse processo de produção de imagens há uma fragmentação da informação (seleção, montagem e edição), para persuadir e conquistar consumidores (público-alvo) específicos. O trabalho realizado é capaz de tornar presente o ausente que existiu, numa forma de seleção do melhor enredo, escolhendo-se os de maior prospecção mercadológica.

Não se tem dúvida de que a informação produzida - inquirida e relatada, no caso do Bairro Praia Grande - contribuiu para agregar mais valor a essa mercadoria, e disseminar novos hábitos de consumo em torno do simulacro e do hedonismo. Nesta lógica, os discursos que passavam a evocar elementos psíquicos e sociais nos indivíduos incluem também uma "alucinação estética do real", do qual há um bombardeio de imagens e objetos fascinantes, em detrimento da mera divulgação das suas características funcionais.

Ao exteriorizar os "criadores" do patrimônio, produz-se uma imagem utópica da tradição, sem vestígios de opressão. Essa criatividade lhe dá uma forma que fala mais para fora do que para dentro, subsidiando uma marca do modo de vida e costumes "autênticos" que, quando são comparados ao real, cria frustrações pelas expectativas, às vezes, impossíveis de serem atendidas quando comparada á vida europeia. Essa divulgação leva os indivíduos a acreditarem naquilo que está sendo dito e a buscarem todo o prazer proporcionado pelo consumo daquilo que se anuncia.

Neste sentido, a imagem que é posta como mediação das construções de representações do imaginário individual e social, na forma de linguagens escritas, sonoras visuais, passam a ter um lugar de centralidade no controle social. Assim sendo, fica expressa a estreita ligação entre a estética do patrimônio e a validade do seu contributo, para definição dos mecanismos de produzir aparências, tal como a arte de persuadir e seduzir os indivíduos.

Esta constatação requer, no entanto, que não seja tomada como inquestionável, mas que seja levantada a hipótese de que o modo particular, como a informação contida na promoção do centro antigo de São Luís, não é isenta de implicações conducentes a dar "invisibilidade" aos problemas que os permeiam. 


\section{O Bairro Praia Grande vivenciado pelos turistas}

É inegável que o crescimento do turismo no Maranhão tem contribuído para a divulgação e visualização da cultura local. Porém, essa fruição turística trouxe também consequências negativas com o descontentamento com o que foi vivenciado. No Livro de Protocolo da Secretaria de Turismo do Estado há várias ocorrências que destacam a insatisfação dos turistas com o bairro Praia Grande. Uma turista relatou sua insatisfação na seguinte forma:

Hoje ao chegar ao posto de Informação da Praia Grande, encontrei a cadeira do atendente arriada no chão, de forma que estava impossibilitada de voar. Junto com outro guia pegamos a cadeira e colocamos atrás da cerca decorativa para que seja reservada para avaliação do seu estado. Quero também falar que o aparelho telefônico encontra-se impossibilitado de ser utilizado, pois o mesmo está causando muito barulho. Venho aqui demonstrar a minha insatisfação. Pois, no meio de todo esse caos o turista não quer nem saber de nada disso, querendo logo é ser atendido; como aqui é de muita importância o telefone está bom; venho dizer que nesta mesma manhã por não poder usar o telefone um turista não ficou muito satisfeito com o atendimento. Sei que não é de costume isso acontecer, mas seria bom que fosse feito a manutenção dos objetos deste local para um bom funcionamento (SECRETARIA DE TURISMO, 2010, s/p).

Parece que desenvolvimento do turismo, apesar de ter sido focado no Programa de Ação para o Desenvolvimento do Turismo no Nordeste PRODETUR/NE ${ }^{10}$, nunca foi prioridade nesse lugar ocupado por diversos patrimônios culturais. A chamada para o turismo, talvez tenha sido um pecado capital para o espaço que tem muitos problemas urbanísticos. Todavia, o caráter dinamizador do turismo em criar centralidade, e até de se constituir um centro, foi imposto com condição de utilizar o vazio perante a sociedade e a cidade.

O valor histórico do patrimônio da Praia Grande propalado pelo poder público não acrescentou muitas coisas, pois criou expectativas e não as atendeu a contento, como relata Sousa (2008, s/p).

O Centro Histórico, tendo à frente o bairro Praia Grande, seguido pelo bairro do Desterro, foi contemplado com a arrojada e necessária iniciativa de restauração e preservação levada a cabo pelo governo estadual. [...] Com o passar do tempo, contudo, o Centro Histórico foi sendo gradativamente abandonado, largado à própria sorte, e os problemas começaram a surgir. Questões como insegurança, falta de limpeza, colocação de cartazes nas paredes dos prédios, iluminação precária ou inexistente, descumprimento às leis que no passado disciplinaram o local se multiplicam a cada dia, ameaçando o título alcançado por São Luís de Patrimônio Cultural da Humanidade.

Admite-se sem qualquer dúvida que o marketing utilizado para promover o bairro Praia Grande deu maior visibilidade ao centro histórico da cidade de São Luís, particularmente no que diz respeito à divulgação dos produtos culturais para os novos consumido- 
res da cultura, e ainda rompeu a organização imaginária, alterando o pensar até então vigente, provocando um movimento abrupto, que com um tempo passou a ser questionado pela comunidade local e pelos turistas.

Para constatar essas implicações, no caso do bairro Praia Grande, basta caminhar pelas ruas da Estrela ou Portugal, que tiveram edificações tombadas pelo IPHAN. Houve reformas de centenas de imóveis, (casarões, teatros, escadarias, praças e logradouros), o que proporcionou a abertura de vários bares, restaurantes, hotéis, pousadas, lojas, estimulados pelo poder público. Entretanto, essa dinamização em volta do patrimônio não conseguiu apagar os problemas que afetam esta área, denunciadas pelos turistas.

Uma reclamação recorrente, percebida no livro consistiu sobre no fechamento de estabelecimentos voltados para a atividade, inclusive os principais museus nos finais de semana e feriados. Na visão de um deles, isso prejudica e frustra sua visita à região.

Deixo aqui a minha insatisfação de encontrar todos os museus e espaços culturais fechados na segunda-feira. A cidade está cheia de turistas do mundo todo e apenas podemos fotografar por fora. Sugestão: manutenção dos museus, fazer no período da noite e abrir para o público de segunda a segunda. Afinal, não estamos num Patrimônio da humanidade! (SECRETARIA DE TURISMO, 2010, s/p).

Encontramos com pesar a cidade parada, com as atrações turísticas fechadas, o que não deveria ocorrer num dia como hoje, quando surge a oportunidade de passear e conhecer São Luís. É observando a separação física de entidades de turismo municipal e estadual no tocante aos escritórios de (não dá para entender hibernação?) turísticos, ainda mais os feriados e a infeliz falta de material de divulgação dos atrativos locais como mapas, restaurantes, hotéis, pousadas, etc... É uma vergonha administrativa espelhando a incompetência dos políticos (SECRETARIA DE TURISMO, 2010, s/p).

Cheguei em São Luís hoje e encontrei todos os museus fechados. Sugiro que os horários de funcionamento sejam revistos em nome do fluxo de turistas nos feriados (SECRETARIA DE TURISMO, 2010, s/p).

Nos comentários foi identificado que os turistas reclamam também dos banheiros, da sujeira e da falta de treinamento de profissionais, o que os deixou indignados. Reclamam da sinalização e do descaso com muitos espaços que não são ocupados. Isto foi constatado nos seguintes relatos:

O banheiro do terminal urbano de integração é péssimo. Não é possível usá-lo. Por isso, gostaria da prefeitura melhorar as condições do lugar porque realmente achei desumano para o pessoal da cidade mesmo (SECRETARIA DE TURISMO, 2009, s/p).

Venho através desta reclamar a cobrança de taxa em banheiro público na Praça Nauro Machado; o fato ocorreu dia 31-10-2008. Onde um funcionário cobrou uma taxa para mim e outro usuário que chegou logo depois... Após o ocorrido fui reclamar no posto policial localizado naquele local, 
onde os mesmos me informaram que a taxa não deveria ser cobrada. Voltei a utilizar novamente o banheiro mais uma vez e o funcionário que estava na portaria, proibiu-me de adentrar, alegando que eu não havia dado boa noite para entrar, e que devido a minha "saliência" eu não utilizaria de um ambiente que é PÚBLICO. Atesto aqui minha indignação com tal fato que envergonha nossa cidade Patrimônio Cultural da Humanidade (SECRETARIA DE TURISMO, 2010, s/p).

Outras das reclamações feitas pelos turistas estão relacionadas com o policiamento e com a falta de iluminação. Questões como insegurança, falta de limpeza, colocação de cartazes nas paredes dos prédios e descumprimento das leis estão presentes nos registros de insatisfação com a área. Com relação à segurança, existe um box da Polícia Militar em frente à Praça Nauro Machado e uma sala da Polícia de Turismo. De acordo com os policiais, o patrulhamento é feito por meio de viaturas. Contudo, o atendimento ainda é desnivelado.

As estratégias de divulgação da Praia Grande para influenciar a venda do espaço tem como objetivo, ao menos em termos midiáticos, dar uma ideia de limpeza da área, do reforço da segurança com certa regulamentação do comportamento das pessoas nos espaços. Representa, por isso, uma narrativa da identidade social sobre o que as pessoas fazem ou deveriam fazer (ZUKIN, 2006).

De acordo com Sousa (2008), que realizou pesquisa com comerciantes da área, no artigo intitulado "o lamentável abandono do Centro Histórico de São Luís" publicado no site JP turismo e no blog CAZOMBANDO, além desse problema, uma grande quantidade de adolescentes tem se aglomerado nos últimos meses, às quintas e sextas-feiras, na praça Valdelino Cécio e na escadaria da Praça Nauro Machado, locais onde esses jovens consomem álcool, cigarro e drogas, visto que não há fiscalização do problema.

Complementando esse cenário, um comerciante, proprietário de uma Livraria, afirma que a ausência do poder público e a iluminação precária são fatos que estimulam a prática de assaltos e roubos na Praia Grande. Ele acrescenta também:

Olha, eu já tive problema de roubo, assim de arrombarem por duas vezes. É muito bêbado, muito marginal circulando por aqui. $E$ eu vejo isso por conta da turista que chega e fica reclamando. Teve uma senhora passando por aqui, muito simpática, ele tinha uns cinqüenta e poucos anos e ela mora no Rio nascida e criada no RJ e ela curiosamente foi assaltada aqui, ela nunca tinha sido assaltada na vida dela e ela foi assaltada aqui no Reviver. E ela dizendo - poh eu moro no RJ desde que nasci e nunca fui assaltada e vim pra cá e fui (ENTREVISTADO).

$\mathrm{Na}$ Secretaria de Turismo tem o seguinte registro de insatisfação de uma turista, dentre outros:

Srs. Responsáveis pela Sec. De Turismo do Maranhão: Sou paraibana, trabalho com educação e estou pela primeira vez em São Luís. Acabo de constatar, com toda indignação possível, o total descaso e abandono com o "NOSSO PATRIMÔNIO CULTURAL DA HUMANIDADE". Jamais esperei presenciar tanta propaganda enganosa veiculada por aqueles que têm 
a OBRIGAÇÃO de preservar a NOSSA HISTÓRIA! Continuarei, por todos os meios possíveis, a protestar em relação ao ESTADO DE ABANDONO em que se encontra o Centro Histórico de São Luís.(SECRETARIA DE TURISMO, 2010, s/p).

De acordo com alguns turistas que vão ao centro histórico, aquela área não está preparada para promover a atividade turística. Isso é também muito reforçado nas falas dos comerciantes. Apesar de ser reconhecido como um dos pedaços mais atrativos da cidade, ainda sofre com a carência de cuidados e conservação. A falta de infraestrutura, bem como o grande assédio aos visitantes, por parte de pedintes e vendedores ambulantes, integram a lista das queixas feitas não apenas pelos visitantes, mas por profissionais da área de turismo.

Um grupo turista de São Paulo registrou o seguinte comentário direcionado ao Secretário de Turismo:

\begin{abstract}
Senhor Secretário de Turismo,
Em visita a essa linda Maranhão especificamente a São Luís, ficamos muito entristecidas com a falta de cuidado com relação aos prédios, limpeza e higiene da cidade. Esperamos ao retornar e ao indicar a nossos colegas que o Centro Histórico mereça uma atenção da "nova" governadora, que é daqui e deveria ter interesse real na melhoria desse Maravilhoso Estado. Somos de São Paulo (SECRETARIA DE TURISMO, 2010, s/p).
\end{abstract}

De acordo com alguns comerciantes, está mais do que na hora de se introduzir mudanças conceituais, formais ou estruturais, para que o centro antigo tenha uma melhor infraestrutura. Portanto, pode-se apostar que a análise e compreensão do espaço para a sua real requalificação serão efetivadas se o poder público estiver presente e atuante, já que só ela tem a prerrogativa de impor políticas orientadoras voltadas para o planejamento e gestão das diferentes atividades e setores econômicos, inclusive do turismo.

Nesse caso, entende-se que a promoção da Praia Grande prepondera o idealismo e a utopia, estendendo o vasto domínio da técnica na produção de mensagens, imagens que penetram no campo da percepção e da inteligibilidade humana e que gozam de uma nova ordem cultural, caminhando para a construção do imaginário. E esse domínio vem refletindo na transformação, na forma de o indivíduo perceber a realidade que só é desmistificada à custa, na maioria das vezes, no consumo do produto turístico, gerando vários descontentamentos.

Infere-se que definir a Praia Grande como um padrão de premissas básicas, inventadas, descobertas ou desenvolvidas, as quais são utilizados para camuflar os problemas, quer em termos de estrutura, quer em termos de falta de gestão, não funciona suficientemente, na medida em que são denunciadas, seja por registros formais, ou mesmo via web por aqueles que se sentem lesados quando confrontam o que foi propalado com o vivenciado. 


\section{Conclusões}

De acordo com as orientações no site do ministério do turismo, no item perguntas frequentes, as reclamações devem ser registradas junto à Secretaria de Turismo da UF correspondente, pois é o órgão responsável pela apuração de irregularidades na região e verificação de providências cabíveis. No caso do Centro Histórico de São Luís, qualquer intervenção impõe um modelo cooperativo, nas quais se ressalta a importância de todas as esferas (Municipal, Estadual e Federal) envolvidas compartilharem da concepção e dos mecanismos de gestão do Patrimônio Cultural da humanidade.

É importante ressaltar que, mediante entrevista com um funcionário da Secretaria de Turismo, não foram emitidos relatórios aos representantes da população, por meio dos Conselhos Municipais e Estaduais, com o objetivo de conscientizar sobre a situação tácita e explícita. Não obstante as especificidades, os registros fazem com que o debate acerca da função, dos resultados e da finalidade do turismo no centro antigo regiões esteja baseado em uma série de fatores que, se não considerados, implicará numa atribulada gestão do espaço urbano.

Isso não quer dizer que o livro de protocolo da Secretaria de Turismo do Estado do Maranhão substitui ou atua de forma concorrente com as estruturas já institucionalizadas para ouvir os turistas. Enfatiza-se, assim, que sua identidade é distinta, porém auxiliar e complementar, às prerrogativas do Ministério do Turismo, das instâncias municipal, estadual e federal. Dessa forma, por meio do protocolo podem ser identificados os pontosproblema, bem como captar as reais necessidades da Praia Grande, ou do Centro Histórico como um todo.

À medida que os turistas se manifestam, por meio de solicitações, reclamações, sugestões e denúncias, possibilitam um mapeamento pontual contendo a real situação do centro histórico. Portanto, o livro tem papel relevante na identificação das necessidades e demandas, tanto na dimensão coletiva, quanto na individual, transformando-as em suporte estratégico para a tomada de decisões no campo da gestão do espaço urbano.

Neste sentido, embora que o livro de protocolo se constitua uma forma de participação dos cidadãos, não implicou numa atitude responsável da prefeitura, já que o livro tem registrado todos os tipos de ocorrência e não são utilizados para tomadas de decisões no espaço urbano, que é competência do governo municipal. Percebe-se, então, na atual conjuntura, que o livro de reclamações não se constituiu um meio célere e eficaz no qual os responsáveis ajam quando, no âmbito da aquisição de bens de consumo ou da prestação de serviços, os turistas entendam que os seus direitos e as suas legítimas expectativas não foram devidamente atendidas.

É preciso atenção para não banalizar ou desmoralizar a função de um livro de protocolo, pois uma instituição só funciona bem se tiver credibilidade junto à população. Por isso, sugere-se que os responsáveis tomem providências cabíveis para que a Praia Grande não seja exposta negativamente pelos turistas nas suas redes de contato de forma pessoal ou via internet. No meio corporativo, fala-se na frase "um cliente insatisfeito passa a imagem negativa para 10 outros clientes". Ou, algo similar. Agora, quando custa um turista insatisfeito? 
Toma-se como máxima que os registros já acumulados no protocolo no âmbito do patrimônio cultural sinalizam insatisfação que se bem utilizados poderiam compor um arcabouço de opiniões e as ideias geradas pelos usuários dos serviços turísticos para implantação de estratégias, trazendo para dentro das decisões da gestão a avaliação, mas por fim configura-se apenas como mais uma alegoria para impressionar o turista.

\section{Referências bibliográficas}

AUGÉ, M. Não-Lugares: Introdução a uma antropologia supermodernidade. São Paulo: Papirus, 1994.

BIANCHINI, F. The relationship between cultural resources and urban policies: issues from European debates. In: DODD, D.: VAN HEMEL, A M. Planning culturaltourism in Europe. Boekman Foundation, Amsterdam, 1999.

BRASILVIAGEM. São Luís, disponível http://www.brasilviagem.com/pntur/?CodAtr=3030 [Data de acesso 12.12. 2009].

BUENO, F. S. Minidicionário da língua portuguesa. São Paulo: FTD: Lisa, 1996.

CARVALHO, H. L. Cartilha informativa: tombamento de bens culturais - (Arquitetura e Urbanismo), IPHAN, 2008.

CIDADES HISTÓRICAS BRASILEIRAS. São Luís. Arquitetura. Disponível em http:// www.cidadeshistoricas.art.br/saoluis/sl arq p.php [Data de acesso: 13.10.2009].

GOVERNO DO ESTADO. Conjunto Arquitetônico. Disponível: http:// governoma.blogspot.com.br/2011/01/conjunto-arquitetonico-de-sao-luis-e-um.html [Data de acesso 12.01. 2011].

HARVEY. D. Condição pós-moderna: uma pesquisa sobre as origens da mudança cultural. 10 ed. São Paulo: Edições Loyola, 2001.

MARANHÃO. Proposta do governo do estado do Maranhão para inclusão do centro histórico de São Luís na lista do patrimônio mundial da UNESCO. (com apontamentos complementares), 2ª versão, São Luís, Maranhão, 1997.

MARQUES, M. T. C. M. Condições de habitabilidade no centro histórico de São Luís-MA: Estudo das atividades comerciais e de serviços necessárias e das atividades incompatíveis. Dissertação de Mestrado em Desenvolvimento Urbano, Universidade Federal de Pernambuco, 2002.

MEIRELES, M. M; TEIXEIRA, A. O. M. O projeto Praia Grande: Subsídios Históricos. In: UFMA-PREXAE, Proposta para recuperação urbana da Praia Grande. Universidade do Maranhão, Pró-Reitoria de Extensão e Assuntos Estudantis - São Luís,1979.

LUCHIARI, M. T. D. P. Turismo, patrimônio cultural e sociedade de consumo. In: Anais do VI Encontro Nacional de Turismo Local, Campo Grande, nov/2002. BAUDRILLARD, J. Simulacros e simulação. Santa Maria da Feira, Relógio d’Água,1991.

PATRIMÔNIO DA HUMANIDADE. Centro Histórico: a Praia Grande. Disponível: http:// www.patrimonioslz.com.br/pagina37.htm [Data de acesso 12.12. 2009].

PORTOS-MA. Cidade Patrimônio da Humanidade. Capital do estado do Maranhão São Luís, 398 anos de história. Disponível em http://www.portosma.com.br/saoluis/index.php [Data de acesso 12.12. 2009].

OLIVEIRA, R.S. Análise das políticas do Estado sobre a preservação do patrimônio histórico e 
cultural de São Luís. Monografia de Ciências Sociais UFMA, 1996.

REIS, R. J. Produção do espaço urbano da Praia Grande. Monografia do Curso de Geografia. Universidade Federal do Maranhão, 1990.

SÀNCHEZ, F. A reinvenção das cidades para um mercado mundial. Chapecó, Argos Ed. Universitária, 2003.

SÀNCHEZ, F. Políticas urbanas em renovação: uma leitura dos modelos emergentes. Revista Brasileira de Estudos Urbanos e Regionais, Campinas, n.1,p.115-132,1999.

SANTO, E.; MARCELO J. (Org.). São Luís: uma leitura da cidade. Prefeitura de São Luís / Instituto de Pesquisa e Planificação da Cidade. São Luís: Instituto da Cidade, 2006.

SECRETARIA DE TURISMO. Livro de Protocolo. Secretaria de Turismo do Estado do Maranhão, 2010.

SILVA, G. P. De volta à Praia Grande: o "velho" centro com o "novo" discurso. Tese (Doutorado) - Universidade Federal do Maranhão, Programa em Políticas Públicas, 2010.

SOUSA, P. M. O lamentável abandono do Centro Histórico de São Luís. JP Turismo. a informação com destino certo. Disponível em: http://cazombando.blogspot.com.br/2011/03/ equipamentos-urbanos-do-centro.html [Data de acesso: 18.11.2008].

STAMOU, A. G.; PARASKEVOPOULOS, S. Images of nature by tourism and environmentalist discourses in visitors books: a critical discourse analysis of ecotourism. London: Sage Publications, 2004. P. 105-129.

VAINER, C.B. Pátria, empresa, mercadoria: notas sobre a estratégia discursiva do Planejamento Estratégico Urbano". In: ARANTES, O.; VAINER, C.B. e MARICATO, E. (orgs.). A cidade do pensamento único: desmanchando consensos. Petrópolis, Vozes, 2000, p.1174.2000a, p.75-103.

ZUKIN, S. Paisagens urbanas pós-modernas: mapeando cultura e poder. In: ARANTES, A. (org.). O Espaço da diferença. São Paulo: Papirus Editora, 2000.

\section{Notas}

${ }^{1} \mathrm{O}$ mix de marketing, também conhecido como composto de marketing ou 4P's, é o conjunto de ferramentas que a empresa utiliza para perseguir seus objetivos de marketing no mercado-alvo. Os 4 "Ps" sugeridos por Philip Kotler são: Product (Produto); Price (Preço); Promotion (Promoção ou Divulgação) e Place (Distribuição).

${ }^{2}$ Avaliando todo o contexto de consumismo na sociedade atual, a divulgação torna-se elemento indissociável, sendo sua atuação fundamental para o funcionamento da engrenagem consumista. Mesmo, reconhecendo as diferenças conceituais, toma-se a palavra, promoção, propaganda, como a forma de tornar algo público, conhecido e desejável para a sociedade de consumo.

${ }^{3} \mathrm{~A}$ ferramenta do marketing, típica das empresas, teve crescente utilização nos planos de cidades, regiões, países, adquirindo diversas denominações ("place marketing", "city marketing", "marketing territorial", "marketing urbano","marketing do lugar", entre outras ) quando se relacionam com a projetação desses espaços, a partir suas singularidades, vocação e especificidades, dentro de cenário de competitividade.

${ }^{4}$ O Centro Histórico de São Luís é composto por vários bairros e compreende o núcleo primitivo da cidade o bairro Praia Grande, onde estão localizados inúmeros imóveis considerados patrimônio cultural. 
${ }^{5}$ Ao analisar a manifestação sensível da mercadoria, Haug (1997) aborda seu aspecto estético, pois é por meio dele que ocorre a fascinação, a sedução do indivíduo, mediante os sentidos. Assim, as formas estéticas, ao atingirem as sensações humanas, causam fascinação e ilusão, uma vez que ofereçam a satisfação buscada pela sua subjetividade (HAUG,1997).

${ }^{6}$ Terreno alagadiço; pântano (BUENO, 1996).

${ }^{7}$ Ludovicense quer dizer natural de São Luís-MA.

${ }^{8}$ Os sobrados: edificações de até quatro pavimentos de uso misto. No térreo, funcionava o comércio e dependências de serviço; nos demais pavimentos, o uso era residencial. Apresentam sacadas em pedra de lioz, e outros balcões corridos em toda a extensão de abertura dos vãos, que são guarnecidos por gradis de ferro com desenhos variados. Um bom número dessas construções possui mirantes (pavimento que aproveita o desvão gerado pela inclinação de telhado (MARANHÃO,1997).

${ }^{9}$ Segundo Carvalho (2008), o tombamento é um ato administrativo realizado pelo Poder Público com o objetivo de preservar, por intermédio da aplicação de legislação específica bens de valor histórico, cultural, arquitetônico, ambiental e também de valor afetivo para a população, impedindo que venham a ser destruídos ou descaracterizados. (CARVALHO, 2008, p. 02).

${ }^{10} 0$ De acordo com Marques (2002), o PRODETUR/NE, em sua primeira fase, foi implantado no Maranhão tardiamente em relação a outros estados da região, já que o contrato de financiamento foi assinado somente em fins de 1998, fazendo com que muitas das ações só fossem finalizadas a partir de 2001 e, muitas delas, alguns anos depois.

Georgia Patrícia da Silva: Instituto Federal de Educação, Ciência e Tecnologia de Roraima, Boa Vista, RR, Brasil.

Email: geoufpe@yahoo.com.br

Link para o currículo Lattes: http://lattes.cnpq.br/8762583706265854

Elizabete Melo Nogueira: Instituto Federal de Educação, Ciência e Tecnologia de Roraima, Boa Vista, RR, Brasil.

Email: betemnogueira@gmail.com

Link para o currículo Lattes: http://lattes.cnpq.br/7571793745280814

Maria Neusa de Lima Pereira: Instituto Federal de Educação, Ciência e Tecnologia de Roraima, Boa Vista, RR, Brasil.

Email:mneusa@gmail.com

Link para o currículo Lattes: http://lattes.cnpq.br/3057814874896619

Data de submissão: 31 de maio de 2012

Data de recebimento de correções: 17 de agosto de 2012

Data do aceite: 17 de agosto de 2012

Avaliado anonimamente 